\title{
Research on the Information Management System of University Student Status Archives
}

\author{
Hong ZHANG \\ Admission and Employment Department \\ Zaozhuang Vocational College of Science and Technology \\ Binzhou, China \\ E-mail: cuijq900@126.com
}

\begin{abstract}
The management system for student status archives information is designed in this paper with taking the information of student status archives as the research object, and combining with the background of current archives management as the current research situation. According to the actual situation of the system for demand analysis, the overall framework of the system is designed, the relevant theory of the system and software development tools is introduced in detail, and the background database of the system is analyzed. The archives management system designed in this paper has been applied to the daily work of our school's archives, which can greatly improve the efficiency of the archives staff.
\end{abstract}

Keywords-archives management; informatization; system design; framework; database

\section{INTRODUCTION}

The management of student status archives in colleges and universities is an indispensable part of the archives management in every university nowadays. Therefore, the informationization of student status archives management system in colleges and universities has become a hot topic of concern. The informationization of archives management is to digitize paper archives and save them through computer network technology and database technology, and to provide them with sufficient information and fast inquiry means. Traditional archives management basically adopts manual collection of paper data management mode, but traditional paper archives have many shortcomings, such as paper is easy to yellowing, mildew, damage, in addition, paper archives will occupy a large amount of space in archives, too high requirements for fire prevention, moisture-proof, low efficiency and difficulty of access and query, and there are human resources consumption, difficult to query and modify, etc. Because of the shortcomings of poor security and low work efficiency, it is urgent to digitize paper files by using tomputer network technology nowadays. The management of student status files in colleges and universities also needs an information-based management tool to provide them with efficient and scientific management means.

\section{NEEDS ANALYSis OF StUdent StATUS MANAGEMENT}

\section{A. Purpose of demand analysis}

The requirement analysis of the system is to better understand the user's needs, accurately and detailedly analyze the user's needs, organize the user's needs into a complete definition, and then reflect the requirements in the function of software design, so as to better improve the design of the system and better serve the users. According to the needs of University archives, this system not only can query, modify and add the basic information of students, colleges, majors and classes, but also has the printing function of Chinese and English transcripts and the import and inquiry of PDF documents.

\section{B. System design objectives}

Student status file management system is designed to manage all kinds of information of students conveniently, quickly and effectively. By using the software system designed in this paper, we can effectively improve the shortcomings of managing student status information manually in the past. The software system not only needs flexible inquiry of student information, such as fuzzy search through student number and name, addition and inquiry of user information, but also requires modification and deletion of students' basic information and grades, as well as upload and download of important documents.

In order to ensure the security of information stored in the system and database, it is generally required in the development of software system that the system can set permission according to the user's role. For example, the system administrator can change the settings of the whole system and the users used. Students can only be allowed to view their own information and modify part of the information, while archives staff has the functions of management and modification. Perfect the function and authority of students' relevant information.

\section{Functional limitations}

The design of application software should have enough ability to prevent misoperation and misinput. Therefore, when designing the important modules of the system, the function of keyboard input restriction is added. When users use this system, 
they can complete a series of operations and perform corresponding functions according to the prompts on the interface. The system sets the function of forbidding the input of characters other than numeric characters for the input of text boxes (only numeric symbols) with special requirements.

\section{OVERALL DESIGN SCHEME}

\section{A. Architecture Module Design}

Modern archives management is becoming more and more digitalized and informationized. Intelligent management is particularly important for the archives management of colleges and universities with large numbers of people and complicated information materials. At present, each university has its own educational administration system, which stores the basic information of students' admission, four-year academic credits, rewards and punishments, and information changes. The system design is mainly connected with the university educational administration system. The student archives information of the archives management system should be taken over from the university educational administration system, and then processed according to the characteristics of the system. This design mainly includes $\mathrm{C} / \mathrm{S}$ architecture system and B/S architecture system.

\section{B. Functional Design of C/S Architecture}

$\mathrm{C} / \mathrm{S}$ architecture is also called Client/Server architecture, which is client/server architecture. This system is only open to archives staff. Only the staff members who have stored information in the information table of the system database can log in to the system through the account password. This system has the function of setting permissions. The staff members can only view and modify the module information within their permissions. System administrators can set staff rights. Archives staff can query, modify, add and delete modules such as colleges, majors, classes and courses. They can also query students' basic information, inquire students' student status files (PDF) information and inquire and print students' Chinese and English transcripts.

\section{Functional Design of B/S Architecture}

B/S architecture, also known as Browser/Server architecture, is browser/server architecture. There are two login roles in this system. Therefore, after successful login, the page will automatically identify the roles and find the corresponding system access pages for different users. Personal information query users can view personal information, and can modify the user's login password. In addition, administrator users can view personal basic information and modify it. Student users can only view personal related information, but can not change it. Students' basic information management can add, subtract, check and delete the basic information related to students. Students' information can also be inquired according to their majors, classes, names and school numbers. Students' user pages can not see the function module. The management of student achievement information can query the achievement information according to the college, specialty, class, course name, student number and student name. The result can be shown in descending order, and the current page information can be printed. Student users can view all the information of their grades, or they can inquire and print according to the course.

\section{Backup and recovery of data}

The technology of database backup means that the stored database information is copied and saved through certain means, and stored elsewhere as a copy for backup, in order to prevent the loss of data information caused by system failure. The technology of database recovery is that once the database content is wrong, the system cannot be accessed, man-made destruction or irresistible factors lead to data loss, the backup database can be used to retrieve the lost data information. The technology of database recovery can be selected according to the way of backup and the degree of data damage. Restoration technology of computer database has limitations. Data information must be stored in computer through physical backup in order to realize the restoring function of database.

The system administrator has the right to backup and restore the database. In the system, the database can be backed up to other locations of the computer, which belongs to physical backup, or the database can be exported through SQL Sever2008 for backup. The recovery function designed in the system can completely restore the backup database information.

\section{E. Introduction and Inquiry of Student Status Archives}

In the archives of colleges and universities, besides the electronic information of students, there are also a large number of paper information archives, such as student's student status card, admission roster, four-year transcripts and graduation thesis reviews. Because there are many defects in paper archives, it is not easy to preserve and consult, so in the design of this system, the staff can digitally preserve the original paper archives. This function requires archivists to scan the existing paper files into PDF format and save the electronic documents in the folder of the computer through electronic scanner, and set the naming format of the electronic documents as "student number_name_file summary.PDF" for easy viewing. In this design, the staff can save the electronic files to the database of the system through the function of $\mathrm{C} / \mathrm{S}$ system, while the students can view and download individual student status files through the function of B/S system design.

\section{FUNCTIONAL ORIENTATION OF ARCHIVES}

\section{MANAGEMENT SYSTEM IN COLLEGES AND UNIVERSITIES}

The design of this system is mainly used to take over the relevant information of the students who will graduate or have graduated in the educational administration system. Therefore, when designing the database related information table, we should refer to the design of the database information table provided by the university educational administration system, in order to prevent the different fields from directly importing. In the design of data information table, the name of each field is simple and easy to understand, so as to facilitate the call of a field in the database when the program is written, and it is composed of commonly used words, which is not easy to make mistakes. 


\section{A. The Evolution of Archives Management in Colleges and Universities}

In the past, archives mainly collected, collated and preserved archives information by collecting paper materials. With the rapid development of computer network information technology, the information society has also affected the form of collecting student status information in University archives, and universities have begun to use the network to publish and collect information.

With the development of computer network technology and database technology, the collection of student status archives information in colleges and universities has changed from traditional paper archives to electronic archives. The use of computer technology to store information is safe and reliable, and can also do backup and redundant processing, which can ensure that the data will not be lost or tampered with various "natural and man-made disasters", and with the large data. With the advent of the times, the archives of colleges and universities will also become a data center with distinct characteristics. How to base the needs of archives of colleges and universities on the needs of data application, achieve high security, reliability and performance, and achieve modularization is a challenging subject.

\section{B. Expansion of Management System Function}

The development of network information technology has put forward further requirements for the management system of university student registration archives. With the increase of University students, more and more users are required to serve the archives, and the data stored in the system has become very huge. This requires that the archives management system of university can synchronize with modern technology, and combine with the network process of information service, take users as the center. It realizes massive storage capacity, fast inquiry means and efficient management system.

In today's information age, most colleges and universities use computer software to manage students' status file information. The functions of the system include class, specialty, college information management and students' basic information management, and the relevant information is stored in the database. Improve the retrieval service function of archives information to facilitate the manager's inquiry of students' information. It is also necessary to improve the publishing function of relevant information so that students can get relevant information in time.

\section{Archives Informatization}

Archives management informationization refers to the use of modern network technology to improve the level of information management of archives, to build a framework of archives management and management methods under the network information environment, so as to improve the information service level of archives management. The construction of archives management informationization must be based on abiding by the relevant rules and regulations issued by the state and making full use of modern information technology, so as to realize the scientific and efficient management of archives information resources and accelerate the pace of its informationization development. The informationization of archives management is a means of archives management with archives information as the main body and modern information technology as the center.

Archives information management is the product of the development of modern computer network technology. It is a modern information archives management technology. It can not only store archives information in electronic form, but also convert the original paper archives into electronic data storage. With the development of multimedia technology, archives management can not only exist in the form of common words and pictures, but also provide voice, image and other forms. The management of archives informationization facilitates the transmission of archives information among different departments, which can be regarded as the transmission between electronic data and network signals.

The informationization construction of archives management mainly depends on the development of computer technology. It can be said that without computer technology, there would be no modern Archives Informationization Management system. The informationization of archives management is to develop the function of data processing based on computer and the storage and processing of computer hardware. In addition, in the use of file management software for data management, the orderly management of data and the continuous updating of information technology are also important factors to promote its development. With the continuous development of computer technology, the information level of archives management will become higher and higher. Therefore, establishing and understanding the relevant rules of enlargement and storage of data information is the prerequisite to improve the information management.

\section{Archives Management Strategy}

With the development of modern computer network technology, if we want to build a comprehensive informationbased archives management system and improve the level of archives management, we must follow certain principles. Only in this way can we quickly realize the informatization of archives management.

It is necessary to build a complete archives management system. To improve the informationization level of archives management, formulate relevant strategies of archives management informationization, and promote the coordinated development of Archives Informationization in colleges and universities, we should strengthen the development and utilization of archives management application software, formulate a standardized electronic archives management system, strictly follow relevant systems and norms, and ensure the management of Archives Informationization in colleges and universities. The system has rules to follow.

Establishing a perfect security system, with the widespread use of archival information, its contents are more and more extensive. There are much archival information related to confidentiality, loss or leakage will cause huge losses. Therefore, it is necessary to establish a sound archival information security system, formulate strict security measures, and ensure the security and confidentiality of relevant 
information. Only when the information system management and information system are implemented in accordance with the rules and relevant requirements, can the security of information management of archives be guaranteed. Informationization is the product of the development of modern science and technology. To realize the informationization of archives in colleges and universities, we must rely on the support of technology. Therefore, strengthening the construction of information technology can better serve the construction of informationized archives management system. To strengthen the construction of information technology is to improve the level of computer, to strengthen the construction of information technology, and to improve the professional skills of archives management staff.

\section{E. Security of Student Status Archives}

Archives management system is mostly based on the local area network of the unit or department, using modern computer network technology and computer processing means, the corresponding data information is stored in the database, so the security of the database directly affects the entire archives management system. Computer viruses, trojans, hackers and other common computer-related threats will become an important factor affecting the security of management systems. In addition, human error operation, network transmission error, physical environment and hardware damage are also important factors affecting The development of archives management system is conducive to more efficient processing of the file information of the staff of the archives management units or departments. The security of its database is very important, especially for large state-owned enterprises, foreign-funded enterprises and national public servants. Once the file information is leaked, it may cause serious consequences for individuals, companies and even the state. For students'information in colleges and universities, once lost or destroyed, it will also bring immeasurable consequences to school managers. the security of management system.

The database backup is to store the database related to the archives management system through physical backup, logical backup, remote backup and so on, in order to prevent the loss of data information. The technology of database recovery is that once the contents of the database are wrong or inaccessible, or the data are lost due to irresistible factors, the backup database can be used to retrieve the lost data information.
Different levels of storage encryption based on the information in the database can prevent illegal users from intruding and stealing information. All information is recorded in the operation log, which can track the information of illegal operators and their illegal operations, and facilitate the recovery of database information.

\section{CONCLUSION}

With the rapid development of modern computer network technology, the management of colleges and universities has also entered the era of information management. How to effectively use modern network technology and database technology to improve the information level of student status file management system has become a hot topic for many scholars. The management of student status information archives is an indispensable part of every university, and its contents are very important for every university. Therefore, it is necessary to develop a management system of student status archives which can provide accurate information and quick inquiry means for University administrators. This system can simplify the manual management of Student Status Archives in the past. It can also make the file management work faster, safer and more effective. It can not only reduce the workload of staff, but also improve the work efficiency.

\section{REFERENCES}

[1] H. Xiuhua. “Archives Informatization for Smart City,” Archives Management, vol.32, pp.206-209, October 2015.

[2] L. Liu-min, H. Guiyun. "New Thoughts on the Management of College Register Archives,” Logic Studies, vol.33, pp. 234-237, August 2016.

[3] L. Hongsheng. "On the Essential Property of College Register Archives and the Management of Register Archives," Education and Occupation, vol. 31, pp. 407-411, January 2014.

[4] L. Qiaohua. "Research on the Information Service Value of College Register Archives in the Digital Age,” Heilongjiang Archives, vol. 01, pp. 464-468, April 2014.

[5] Q. Canwen. "Research on the Information Network Management System of College Student Records,” Electronic Testing, vol.3, pp. 4547, June 2018.

[6] Z. Zhiguo, P. Yugang. "Discussion on the Digital Scientific Management of College Register Archives,” Archives and Construction, vol.24, pp.208-215, July 2015. 